J. Dairy Sci. 95:6937-6945

http://dx.doi.org/10.3168/jds.2012-5734

(C) American Dairy Science Association ${ }^{\circledR}, 2012$.

\title{
The effect of milk fat globules on adherence and internalization of Salmonella Enteritidis to HT-29 cells
}

\author{
A. Guri, ${ }^{\star} \dagger^{1}$ M. Griffiths, ${ }^{*} \dagger$ C. M. Khursigara, $\neq$ and M. Corredig ${ }^{\star}$ \\ *Department of Food Science, University of Guelph, Guelph, Ontario, Canada N1G2W1 \\ †Canadian Research Institute for Food Safety, University of Guelph, Ontario, Canada N1G2W1 \\ ‡Department of Molecular and Cellular Biology, University of Guelph, Guelph, Ontario, Canada N1G2W1
}

\section{ABSTRACT}

Milk fat globules were extracted from bovine and goat milk and incubated with HT-29 human adenocarcinoma cells to assess the attachment and internalization of Salmonella Enteritidis. Because the expression of bacterial adhesins is highly affected by the presence of antibiotic, the attachment was studied with and without antibiotic in the cell growth medium. Although no inhibitory effect of the fat globules was observed in the presence of the antibiotic, milk fat globules significantly inhibited the binding and internalization of Salmonella in medium free of antibiotic. The fat globules from both bovine and goat milk markedly reduced bacterial binding and invasion compared with controls, and the cells treated with goat milk-derived fat globules demonstrated greater protective properties than those derived from bovine milk. The effect of heat treatment on bovine fat globules was also investigated, and it was shown that the fat globules from heated milk had a higher degree of inhibition than those from unheated milk.

Key words: milk fat globule, Salmonella Enteritidis, adherence, HT-29 cell

\section{INTRODUCTION}

Milk fat globules consist of a triglyceride core stabilized by a complex milk fat globule membrane (MFGM), which is derived from the apical plasma membrane of the mammary epithelial cells (Schroten et al., 1992; Brisson et al., 2010; Ye et al., 2010). It has been suggested that the supramolecular structure of the MFGM plays a major role in the delivery of bioactive molecules contained in the MFGM, such as the unique polar lipids, immune-stimulating peptides, and signaling molecules (Dewettinck et al., 2008; Jiménez-

Received May 15, 2012.

Accepted August 19, 2012.

${ }^{1}$ Corresponding author: aguri@uoguelph.ca
Flores and Brisson, 2008). Of specific relevance to the present research, it has been suggested that MFGM components can serve as a target for bacterial adhesion (Atroshi et al., 1983).

Adherence of bacteria to intestinal epithelial cells is considered an important step for colonization by different pathogenic and nonpathogenic microorganisms (Kerneis et al., 1994). Salmonella enterica serovar Enteritidis (Salmonella Enteritidis) is an important foodborne enteric pathogen that has been shown to use specific mechanisms of molecular binding to both biotic and abiotic surfaces. These mechanisms have been studied extensively and clearly demonstrate the involvement of different fimbriae structures in mediating bacterial biofilm formation (Allen-Vercoe et al., 1997; Austin et al., 1998; Desin et al., 2011). Binding to intestinal epithelial cells is frequently used in adherence assays as an indicator of potential virulence and pathogenicity (Kim et al., 2008; Mellor et al., 2009).

Pathogens use specific cell surface glycan epitopes, mucins, lactadherin, and gangliosides as binding sites for their pathogenesis. These same molecules (i.e., glycoproteins, mucins, and glycosphingolipids) have been implicated in the defense of newborns against pathogens (Schroten et al., 1998; Newburg, 2009). In particular, MUC-1 (mucin 1), which is a major MFGM protein, has recently been shown to bind gram-negative bacteria in vitro (Sando et al., 2009; Parker et al., 2010). In vivo trials using BALB/cA mice have shown that bovine milk glycoconjugates may play a role in the inhibition of Helicobacter pylori infection. The actual active molecule involved in the inhibition has not been reported, but MFGM and defatted MFGM displayed similar effects on the healing of infected mice: both inhibited hemagglutination of $H$. pylori at similar concentrations and reduced its binding to HeLa S3 cells (Wang et al., 2001). Recently, it was also reported that milk fat globules, MFGM as well as the glycosphingolipid lactosylceramide and the gangliosides GM3 and GD3, were able to inhibit the binding of enterotoxigenic E. coli strains and prevent their hemagglutination (Sánchez-Juanes et al., 2009). 
To date, no studies have been carried out on the ability of milk fat globules to affect attachment to and colonization of intestinal cells by pathogenic bacteria. The objective of this work was to investigate the possible inhibition of attachment of Salmonella Enteritidis to a human cell line. Salmonella Enteritidis is an important foodborne enteric pathogen as well as the second most commonly isolated serovar of Salmonella after Salmonella enterica serovar Typhimurium in Canada (Poppe, 1994; EFSA, 2011).

The attachment of Salmonella Enteritidis was evaluated by incubating the pathogenic bacteria with milk fat globules on a colon cancer cell line, the adenocarcinoma HT-29 line. These cells have been extensively characterized and shown to be a physiologically relevant model of the parental tissue from which they were derived; they also represent one of the primary sites of Salmonella intestinal infection (Mellor et al., 2009). The potential inhibitory effect of the milk fat globules was investigated using milk fat globules extracted from 2 different sources, bovine and goat milk.

\section{MATERIALS AND METHODS}

\section{Isolation of the Milk Fat Globules from Milk}

Untreated bovine milk was obtained fresh from the dairy research station of the University of Guelph (Ponsonby, ON, Canada), and untreated goat milk was obtained from a local dairy (Woolwich Dairy Inc., Orangeville, ON, Canada). The bovine milk was also heated at $80^{\circ} \mathrm{C}$ for $10 \mathrm{~min}$ before separation. The fat globules (for both bovine and goat milk) were extracted by centrifugation at $4,000 \times g$ for 25 min at $4^{\circ} \mathrm{C}$ using a Beckman J2-21 centrifuge (Beckman Coulter, Mississauga, ON, Canada). The cream layer was removed and washed twice with PBS ( $\mathrm{pH} 7.4)$, and then centrifuged again at 3,200 $\times g$ for 5 min at $4^{\circ} \mathrm{C}$ (Allegra 2IR, Beckman Coulter) and thoroughly dried with filter paper (Whatman 934-AH; Fisher Scientific, Mississauga, ON, Canada). Samples were kept at $4^{\circ} \mathrm{C}$ for the duration of experiments. Milk fat was then resuspended in PBS at ratios of 200 or $400 \mathrm{mg}$ in $1 \mathrm{~mL}$ of buffer and equilibrated to $37^{\circ} \mathrm{C}$ for 5 min before commencing the experiments.

\section{Bacteria and Cell Culture}

Salmonella Enteritidis Lux CDABE (pH l) was obtained from the Canadian Research Institute for Food Safety culture collection (Guelph, ON, Canada). The strain was cultured in Luria-Bertani (LB) broth (Becton Dickinson and Company, Mississauga, ON, Canada) at $37^{\circ} \mathrm{C}$ overnight.
A human colon carcinoma HT-29 cell line was grown in Dulbecco's modified Eagle medium (DMEM) (containing $25 \mathrm{~m} M$ glucose; Invitrogen Canada Inc., Burlington, ON, Canada) in $75-\mathrm{cm}^{2}$ flasks at $37^{\circ} \mathrm{C}$ in a $5 \% \mathrm{CO}_{2}$ atmosphere at constant humidity. The medium was supplemented with $10 \%$ heat-inactivated (30 min, $56^{\circ} \mathrm{C}$ ) fetal bovine serum (Invitrogen Canada Inc.), 2 $\mathrm{mmol} / \mathrm{L}$ of L-glutamine (Sigma-Aldrich Canada Ltd., Oakville, ON, Canada), and a 1\% antibiotic solution of penicillin-streptomycin (100 U of penicillin and 50 $\mu \mathrm{g}$ of streptomycin; Invitrogen, Canada Inc.) and was changed every $2 \mathrm{~d}$. Media with antibiotic and with no antibiotic were used for the assays. Passages were carried out weekly using trypsin-EDTA $[0.25 \%$ trypsin, $1 \mathrm{~m} M$ EDTA.4Na (1×); Invitrogen Canada Inc.]. For bacterial binding assays, the cells were seeded at a concentration of $5 \times 10^{4}$ cells per well in 24-well tissue plates (Corning Glass Works, Mississauga, ON, Canada) containing $1 \mathrm{~mL}$ of complete growth medium. Experiments were performed at 85 to $90 \%$ confluence, which was reached after $72 \mathrm{~h}$ of incubation at $37^{\circ} \mathrm{C}$. Before the assay for adherence and internalization, cells were washed 4 times with PBS to remove nonviable cells.

\section{Determination of the Average Size of the Milk Fat Globules}

The particle size distribution of milk fat globules for both bovine and goat raw milk was determined by using integrated light scattering (Mastersizer 2000; Malvern Instruments, Southborough, MA). The volume-weighted mean particle size $\left(\mathrm{d}_{4,3}\right)$ was recorded. Refractive indexes of 1.33 and 1.46 were used for the water and the fat globules, respectively.

\section{Cell Viability}

The effect of milk fat globules on cell viability was tested before performing the adherence and internalization assay. After growth for $72 \mathrm{~h}$ at $37^{\circ} \mathrm{C}$ in 24 -well plates, cells were washed with $1 \mathrm{~mL}$ of PBS to remove nonviable cells. To each well, $900 \mu \mathrm{L}$ of DMEM was added immediately, together with $100 \mu \mathrm{L}$ of milk fat globule suspensions, to achieve a final concentration of fat globules of 20 or $40 \mathrm{mg}$ for each well. The cells were then incubated for $6 \mathrm{~h}$ at $37^{\circ} \mathrm{C}$ under $5 \% \mathrm{CO}_{2}$. Cells were washed 4 times with PBS and then trypsinized with $200 \mu \mathrm{L} /$ well of trypsin-EDTA for 5 min. Trypan blue $0.4 \%$ was used to stain the cells at a ratio of $1: 10$ ( $\mathrm{vol} / \mathrm{vol}$ ). The cells were then counted with a hemocytometer (Bright-Line Hemacytometer; Reichert, Buffalo, NY) on a light microscope (Axiovert 25; Zeiss, Göttingen, Germany). 


\section{Adherence Assay}

Monolayers of HT-29 cells were prepared as described above. The final dilution of bacteria in DMEM used for bacterial infection was $10^{8} \mathrm{cfu} / \mathrm{mL}$. All adherence assays were carried out in complete medium (regular medium for growing cells) and incomplete medium (only DMEM, with no antibiotic added). The presence of antibiotic has been shown to reduce binding (Beachey et al., 1981; Katsikogianni and Missirlis, 2004). The experiments were carried out using different sequences for addition of Salmonella and fat globules. The cells were incubated for $3 \mathrm{~h}$ with $100 \mu \mathrm{L}$ of bacterial suspension, after which $100 \mu \mathrm{L}$ of milk fat globule suspension was added and the incubation was continued for a further $3 \mathrm{~h}$, or the order of addition of bacteria and the milk fat globule suspension was reversed. The control sample was incubated for $6 \mathrm{~h}$. All samples were incubated at $37^{\circ} \mathrm{C}$ under $5 \% \mathrm{CO}_{2}$. After incubation, cells were washed 4 times with PBS to remove unattached bacteria, and $200 \mu \mathrm{L}$ of trypsin-EDTA per well was added. After incubation for $5 \mathrm{~min}$ at $37^{\circ} \mathrm{C}$ in $5 \% \mathrm{CO}_{2}$, the adherent cells were detached by vigorous pipetting.

To quantify the attachment to the cells, serial 10-fold dilutions in PBS were prepared, and $100-\mu \mathrm{L}$ aliquots were plated onto LB agar (Becton Dickinson and Company) plates and incubated at $37^{\circ} \mathrm{C}$ for $18 \mathrm{~h}$. Results are presented as log colony-forming units per well of associated bacteria. The assay was performed in duplicate with independently grown bacterial cultures.

\section{Internalization Assay}

The internalization of Salmonella Enteritidis was determined by enumeration of the intracellular bacteria, using a previously published gentamicin protection assay (Gordon et al., 2005) with slight modifications. Infected HT-29 cells were washed 3 times with PBS and incubated with $200 \mu \mathrm{g} / \mathrm{mL}$ of gentamicin for 30 min at $37^{\circ} \mathrm{C}$ in a $5 \% \mathrm{CO}_{2}$ atmosphere. This killed the cell-associated (and not internalized) bacteria. The final washed dispersions (without the cells) were then plated as a control for the gentamicin treatment. Cells were osmotically lysed by adding sterile water and incubated for $30 \mathrm{~min}$ on ice. The suspensions were then collected and appropriate dilutions were plated on LB plates, as described above. Colonies were counted after incubating the plates for $18 \mathrm{~h}$ at $37^{\circ} \mathrm{C}$. Association and invasion assays were performed in duplicate (4 wells/ test). As already described for the adherence assays, the internalization tests were performed in complete and incomplete cell growth media.

\section{Transmission Electron Microscopy}

For transmission electron microscopy (TEM), cells were grown in culture plates (Corning Glass Works), and incubation with fat globules, bacteria, or both was performed following the same protocol as described for the adherence assays. After washing with PBS, the cells were scraped and fixed in glutaraldehyde $(2.5 \%)$ for $1 \mathrm{~h}$, and then washed with $0.1 M$ cacodylate buffer $\left(\mathrm{pH} \mathrm{7.4)}\right.$ at $4^{\circ} \mathrm{C}$ for 30 min. After 3 washes with cacodylate buffer, cells were postfixed in $1 \%$ osmium tetraoxide for $45 \mathrm{~min}$, washed 3 times with distilled water, and dehydrated using a graded series (50 to $100 \%$ ) of ethanol. Cells were embedded in Nobel agar, sectioned, and then stained in $2 \%$ uracil acetate and $1.5 \%$ lead citrate. Specimens were examined using a Philips CM-10 transmission electron microscope (FEI Co., Eindhoven, the Netherlands) operating at $80 \mathrm{kV}$ under standard operating conditions, and images were collected using a SIS/Olympus Morada 11-megapixel CCD camera (Olympus Soft Imaging Solutions GmbH, Münster, Germany).

\section{Statistical Analysis}

Statistical analysis was performed using Minitab 16 software (Minitab Inc., State College, PA). Differences between means were determined using linear regression and Tukey's test method at a 95\% confidence level.

\section{RESULTS AND DISCUSSION}

\section{Differences in the Physical Properties of the Fat Globules}

The particle size distribution of the milk fat globules in bovine and goat milk was measured by integrated light scattering spectroscopy. The average sizes $\left(\mathrm{d}_{4,3}\right)$ of the milk fat globules were approximately 4.2 and $3.7 \mu \mathrm{m}$ for bovine and goat milk, respectively. Figure 1 compares the cumulative size distribution of bovine and goat milk fat globules, indicating smaller sizes for goat milk fat globules, in agreement with published data (Parkash and Jenness, 1968). However, it is possible to hypothesize that such small differences in size may not be the cause of any significant change in the inhibitory behavior of the fat globules because their specific surface area is comparable. On the other hand, the FA composition of goat milk fat is different from that of bovine milk fat, with the former containing a much higher proportion of short- and medium-chain FA (Park et al., 2007). Short- and medium-chain FA have 


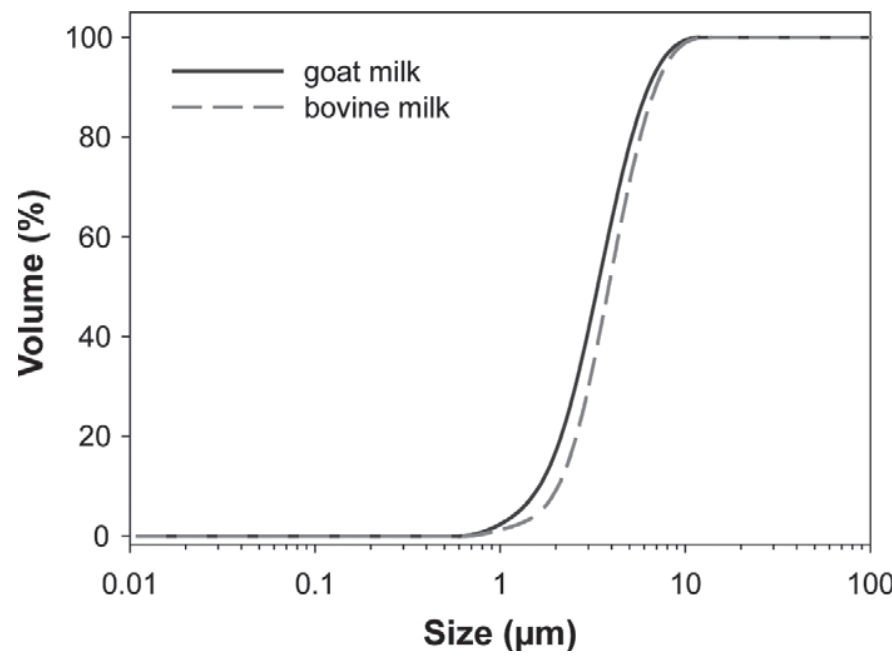

Figure 1. Cumulative size distribution of milk fat globules of raw bovine and goat milk. Distributions shown are the average of 2 replicate experiments.

been shown to have antimicrobial properties (Van Immerseel et al., 2004).

\section{Cell Viability}

The effect of milk fat globules on the viability of the HT-29 colon cancer cells was assessed before conducting further experiments on adherence and internalization (data not shown). No effect of the fat globules on the viability of HT-29 cells was observed when compared with the control. After $6 \mathrm{~h}$ of incubation with bovine milk fat, the cells were fully viable. The results were not surprising because milk is a good source of nutrients to support cell growth.

\section{Adherence Assay}

Fat globules were extracted from nonheated or heated bovine milk and nonheated goat milk. The adherence assays were performed with (Figure 2A) or without (Figure 2B) antibiotic in the growth medium. Because cells had different incubation times with bacteria, control experiments with infection lengths of 3 and $6 \mathrm{~h}$ were carried out. Indeed, because the samples treated with milk fat globules first were infected with bacteria for $3 \mathrm{~h}$, the cells treated with milk fat globules after infection were exposed to the pathogen for a total of $6 \mathrm{~h}$. Because no significant differences were observed between the 2 controls, only experiments with cells incubated with Salmonella for $6 \mathrm{~h}$ were used as the control. The origin of the milk fat (goat vs. cow), the treatment (heated or nonheated), and the concentration effects were evaluated.
Control experiments carried out with complete medium (containing antibiotics) showed a low number of bacteria, only $3.2 \log \mathrm{cfu} /$ well (Figure $2 \mathrm{~A}$ ). In this case, the treatments showed a statistically higher number of bacteria compared with the control, possibly because of the presence of growth fractions in the milk samples not present in the control (Figure 2A). The order of ad-
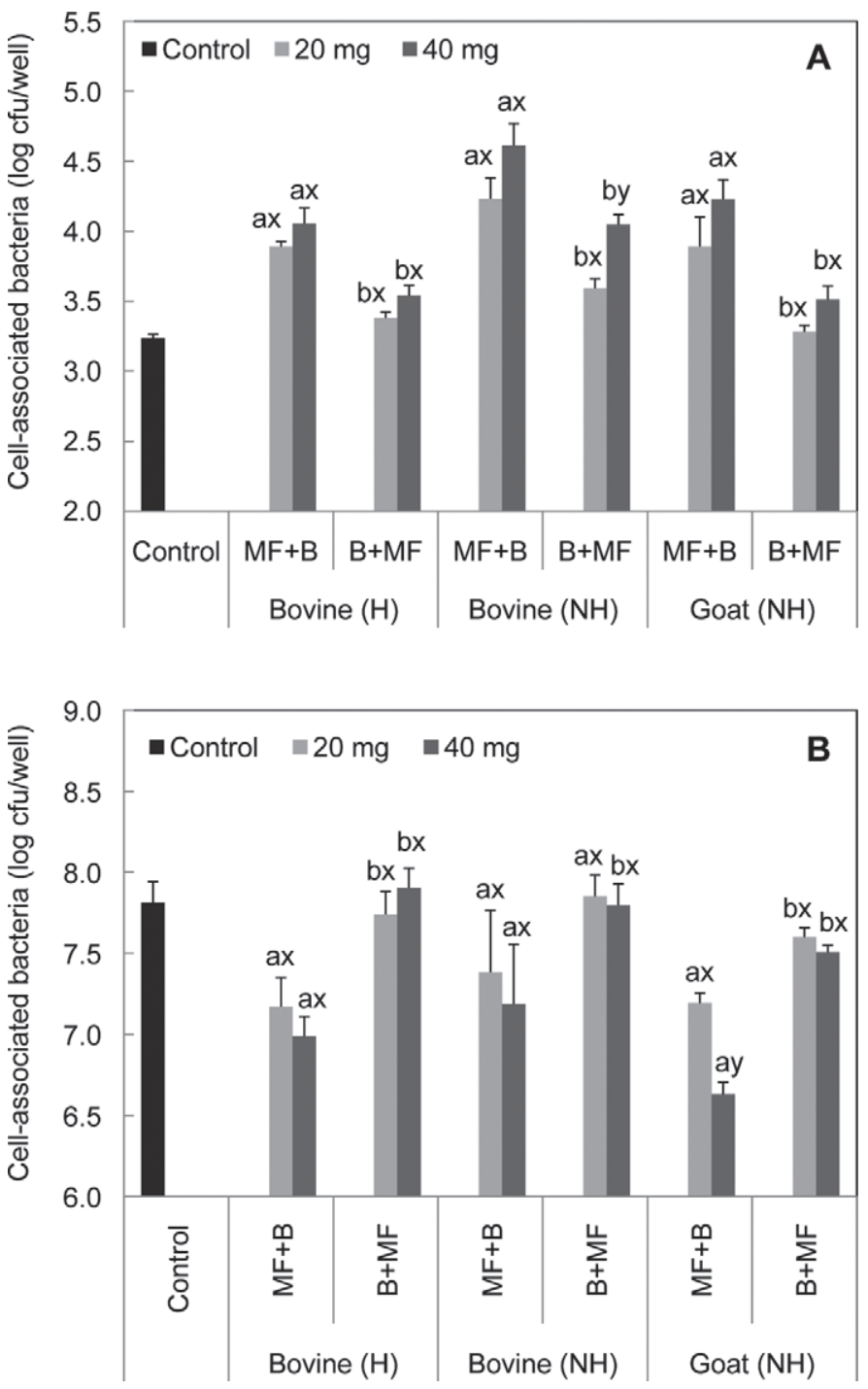

Figure 2. Effect of milk fat globule (MF) suspensions (20 and 40 $\mathrm{mg} /$ well) on the adherence of Salmonella Enteritidis to HT-29 cells grown in complete (with antibiotic) medium (A) or incomplete medium (B). Bovine MF were extracted from heated $(\mathrm{H})$ bovine milk and nonheated $(\mathrm{NH})$ bovine or goat milk. The order of exposure to the cells is shown as $\mathrm{B}+\mathrm{MF}$ or $\mathrm{MF}+\mathrm{B}$ for bacteria added before or after the milk fat suspension, respectively. Control samples were infected with Salmonella for the total duration of the experiment, 3 or $6 \mathrm{~h}(3 \mathrm{~h}$ not shown). The values are the average of 3 replicates (4 wells/sample), with standard deviations. Different lowercase letters show significant differences within samples for the order of addition of milk fat globules $(\mathrm{a}, \mathrm{b})$ and for concentration effects $(\mathrm{x}, \mathrm{y})$. 
dition of fat globules or bacteria resulted in a statistically significant difference in the number of Salmonella attached for each treatment, with a lower number of adherent bacterial cells observed when the fat globule suspension was added $3 \mathrm{~h}$ after incubation of the HT29 cells with bacteria. On the other hand, when the cells were exposed to the fat globules first and then infected with Salmonella, a higher number of bacteria were attached to the cells compared with the control. It is important to note that, in this case, the cells were incubated with the pathogen for only $3 \mathrm{~h}$, and the HT-29 cells showed a lower extent of disruption, as discussed below (see Figure 3). This may have contributed to the higher number of bacterial cells recovered in these samples compared with those incubated for $6 \mathrm{~h}$.

In addition, for the nonheated fat globules isolated from goat or bovine milk, an increase in the level of bacteria attached to the cells was observed, compared with those in the control samples. The effect of concentration was not pronounced; however, a higher number of bacterial cells were attached for the nonheated fat globules from bovine milk, whereas for goat milk fat globules, this effect was shown only when the fat was added before infection. As mentioned previously, this is probably due to the difference in the components present in the media in the samples with milk fat globules affecting the growth of the cells.

The presence of antibiotic in the medium can affect the expression of the adhesive ligands that bacteria need for attachment to mucosal surfaces (Beachey et al., 1981; Katsikogianni and Missirlis, 2004). For this reason, to test possible differences in the adhesion of Salmonella on HT-29 cells, the same experiments were also performed with incomplete medium, as shown in Figure 3B. In this case, a higher number of bacteria adhered to the HT-29 cells compared with those adhering to the control.

The control sample recovered $7.8 \mathrm{log} \mathrm{cfu} /$ well of Salmonella attached to the cells, which was about $60 \%$ more than that observed when antibiotic was present in the growth medium. This difference in attachment confirmed the results of previous studies showing that antibiotic can cause 70 to $80 \%$ inhibition of bacterial binding to cells at these sublethal doses of antibiotic (Beachey et al., 1981). The difference in the results shown in Figure 2A and 2B suggested once again that the presence of antibiotic affected the expression of molecules involved with mucosal colonization.

The adherence experiments in complete medium (Figure 2A) showed very different results compared with those performed in medium with no antibiotic (Figure 2B). Apart from the higher number of bacteria attached to the cells in all treatments with incomplete media, a clear decrease was observed in the number of bacteria attached to the cells for the samples treated first with milk fat compared with the ones incubated with bacteria. The effect of milk fat globules on adherence was not significant in experiments performed in complete medium. The addition of the milk fat globule suspension before the inoculation of bacteria caused statistically significantly lower binding compared with control samples or samples in which fat globules were added after Salmonella infection. The samples with addition of the fat globule suspension after infection showed similar attachment as those for the control experiments (to be compared also with the higher numbers shown with complete media in Figure 2A). From the results, it was possible to conclude that the presence of milk fat inhibited attachment to the cells to a greater extent when the fat globules were extracted from heated rather than nonheated milk. It has been widely reported that heating denatures MFGM proteins and that heat-induced interactions occur between MFGM components and whey proteins in milk, such as $\beta-\mathrm{LG}$ and $\alpha$-LA, at temperatures as low as $60^{\circ} \mathrm{C}$ (Kim and Jiménez-Flores, 1995; Corredig and Dalgleish, 1996). Hence, it may be possible that the inhibition of Salmonella binding is caused by heat-labile components in the MFGM.

The inhibitory effect of the fat globules was also shown in goat milk (Figure 2B). Regarding the fat globules from bovine milk, a statistically significantly lower number of bacteria were observed in the samples treated with milk fat from goat milk than in those derived from bovine milk.

In the experiments with goat milk fat globules at a level of $40 \mathrm{mg} / \mathrm{mL}$, a reduction in adherence of $16 \%$ was observed, whereas for those using fat globules from bovine milk, the reduction was 8 and $11 \%$ for nonheated and heated milk, respectively. It has previously been reported that goat milk has a higher portion of small fat globules compared with the proportion in bovine milk (Parkash and Jenness, 1968; Silanikove et al., 2010). This would translate to a higher binding surface for bacteria in fat globules from goat milk than from bovine milk; however, the differences in the size distribution of the fat globules could not be clearly distinguished when using integrated light scattering spectroscopy (Figure 1). Perhaps a more important difference between goat and bovine milk fat globules is in their chemical composition: goat milk fat is higher in medium-chain FA, and these compounds have been associated with antibacterial properties as well as other health-promoting properties (Van Immerseel et al., 2004; Shingfield et al., 2008). It is important to point out that at this point, the difference, although statistically significant, cannot be related to a possible difference in efficacy in vivo between the 2 fat globule types. 

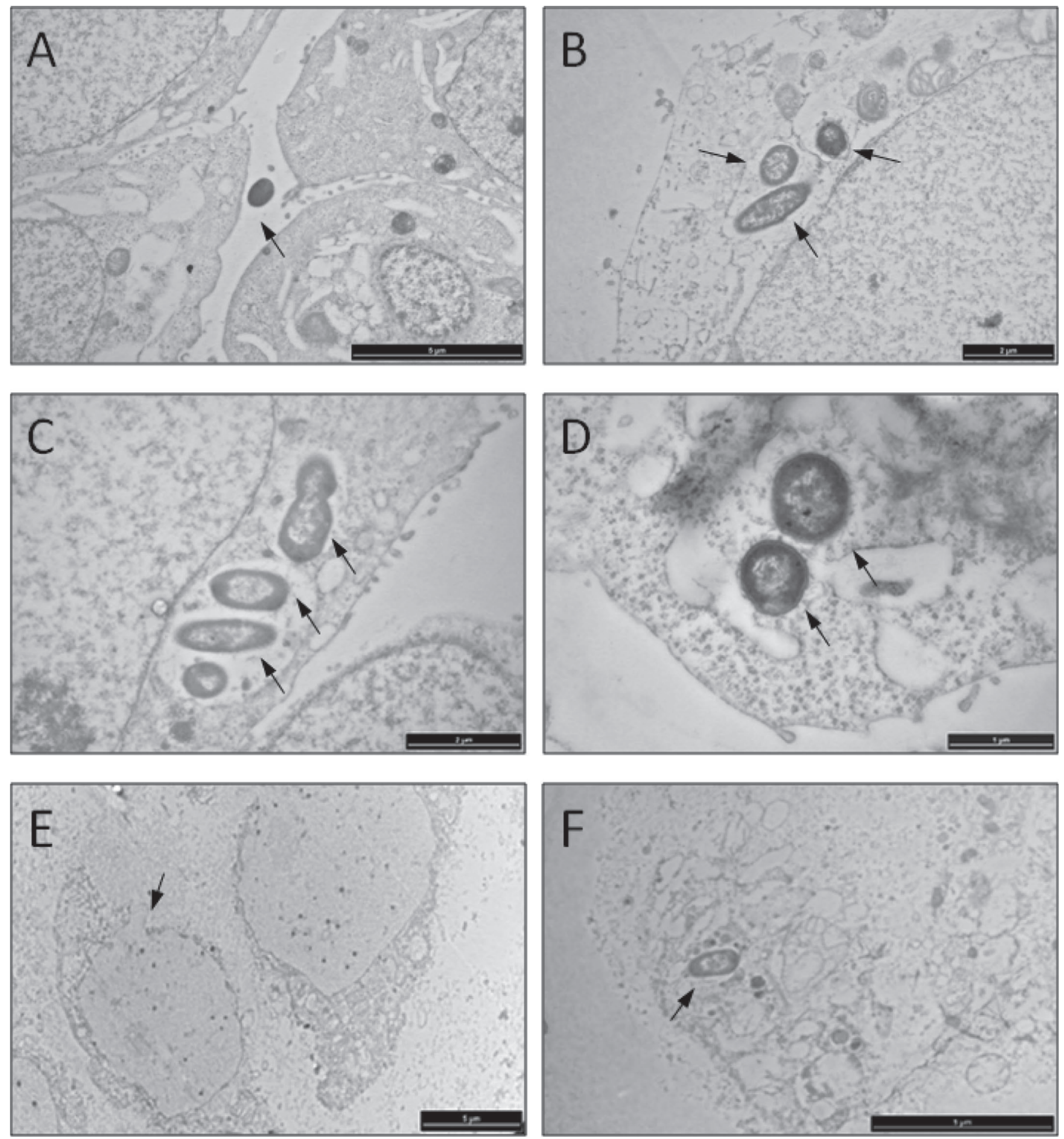

Figure 3. Transmission electron microscopy images of the internalization of Salmonella Enteritidis to HT-29 cells. A-D: cells were preincubated with milk fat globules (MF). E and F: MF was added after infection of the cells. In all cases, medium with antibiotic was used. The arrows show the presence of bacteria attaching (A) or invading the cell (B-D) or cell disruption (E, F). A (bar $5 \mu \mathrm{m}), \mathrm{B}(\mathrm{bar} 2 \mu \mathrm{m}), \mathrm{C}(\mathrm{bar} 2$ $\mu \mathrm{m}), \mathrm{D}($ bar $1 \mu \mathrm{m}), \mathrm{E}$ and $\mathrm{F}$ (bar $5 \mu \mathrm{m})$. 
TEM

Because the adherence assays clearly showed that Salmonella was associated with the HT-29 cells, their internalization into the cells was verified by means of TEM (Figure 3). The results shown were performed in complete medium containing antibiotic. Bacterial cells were found to be associated with the cell membrane (Figure $3 \mathrm{~A})$. In all the images taken from cell cultures with fat globules added before infection (Figure 3A-D), no milk fat residue was located intracellularly or intercellularly. Bacteria were clearly identified inside the HT-29 cells, and the bacterial cells were also shown to be capable of division (Figure 3C). The presence of Salmonella in the Salmonella-containing vacuoles (Figure 3B) helps them survive and replicate in the host cell (Steele-Mortimer, 2008). In the case of cells preincubated with bacteria, membrane integrity was affected and the infection was more advanced compared with the cells preincubated with milk fat (Figure $3 \mathrm{E}$ and $\mathrm{F}$ ). This explains the differences in the number of bacterial cells between the samples treated with milk fat before or after the infections (Figure 2). On the other hand, the longer time of incubation also gives rise to a greater number of bacterial cells internalized, which leads to cell disruption and death because cell monolayer permeability increases with cell death caused by infection (Dobos et al., 2000).

\section{Internalization}

The extent of internalization was determined after treating the infected cells with gentamicin. This antibiotic is not metabolized by the cell, and it will affect only the bacteria present on the surface of the HT-29 cells. After gentamicin treatment, it was possible to determine the effect of the exposure of milk fat globules on the internalization of Salmonella. Figure 4 summarizes the results of the experiments carried out using complete growth media [with antibiotic (see above); Figure 4A] or incomplete media (Figure 4B). In agreement with the results on adherence, it was possible to see the protective effect of milk fat globules only in media without antibiotic.

In the case of experiments using complete medium (Figure 4A), as was mentioned above for the adherence assay, the number of bacteria internalized was significantly higher than the number in the control for the samples preincubated with milk fat. This was most probably caused by the presence of several growth factors in the samples containing milk fat suspensions. No differences were observed between the order of addition or the treatments. On the other hand, the internaliza- tion data shown in Figure 4B confirmed the results of the adherence assays.

The number of intracellular bacteria recovered in the control samples was markedly higher $(60 \%)$ when compared with that of control cells grown in the presence of antibiotic (Figure 4A). In all cases, the exposure of the cells to fat globules before the infection inhibited the internalization of Salmonella, whereas addition of milk fat after exposure of the cells to the bacteria did
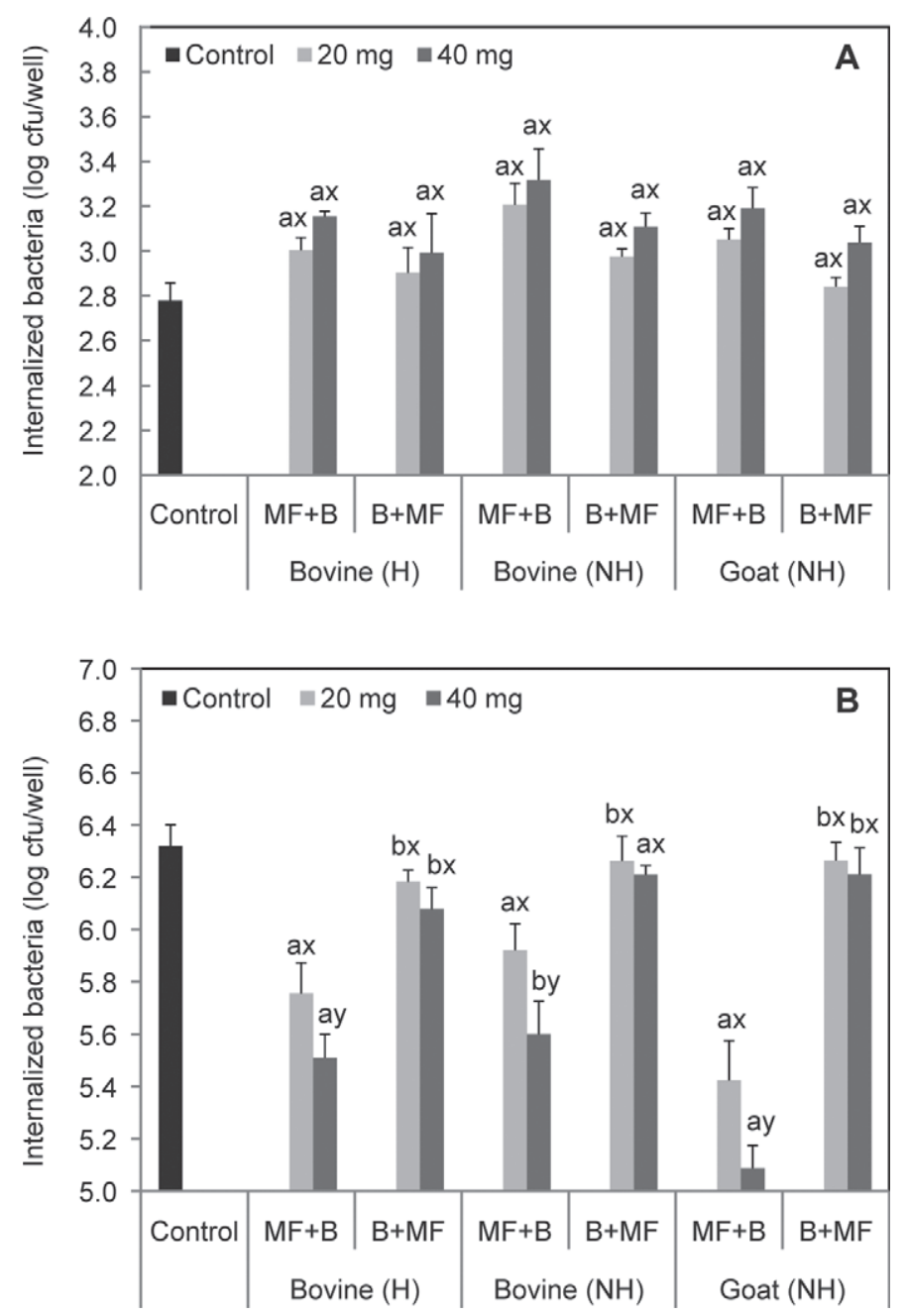

Figure 4. Effect of milk fat globule suspensions (20 and $40 \mathrm{mg} /$ well) on the internalization of Salmonella Enteritidis to HT-29 cells grown in complete (with antibiotic) medium (A) or incomplete medium (B). Bovine milk fat globules (MF) were extracted from heated $(\mathrm{H})$ bovine milk and nonheated $(\mathrm{NH})$ bovine or goat milk. The order of exposure to the cells is shown as $\mathrm{B}+\mathrm{MF}$ or $\mathrm{MF}+\mathrm{B}$ for bacteria added before or after the milk fat suspension, respectively. Control samples were infected with Salmonella for the total duration of the experiment, 3 and $6 \mathrm{~h}$ ( $3 \mathrm{~h}$ not shown). The values are the average of 3 replicates (4 wells/sample), with standard deviations. Different lowercase letters show significant differences within samples for the order of addition of milk fat globules (a, b) and for concentration effects (x, y). 
not show statistically significant differences from the control. Because the order of addition of the milk fat was statistically different for all treatments, for the concentration effect it was shown only for the samples of fat added before bacteria. No such significant differences were found between fat globules isolated from heated and nonheated milk, whereas such differences did exist between bovine and goat milk. Goat milk showed the greatest extent of protection. These findings are in agreement with those of previous studies. It has been reported (Atroshi et al., 1983) that washed MFGM from sow milk significantly inhibited the adherence of K88-positive Escherichia coli to the intestinal brush border membranes and that the fat globules may adhere bacteria through their surface Ig. In addition, it was shown that human milk fat globules can inhibit the adhesion of S-fimbriated $E$. coli to buccal epithelial cells and the addition of human MFGM resulted in 55\% inhibition (Schroten et al., 1992). It was hypothesized that the glycocompounds present on the surface of milk fat function as analogs to mucosal receptors for bacteria (Schroten et al., 1992). However, the effect of short- or medium-chain FA and of the phospholipids present in the membrane of fat globules may also play an important role because the origin of the milk, as well as heating of the milk, affects the protective properties of the fat globules.

\section{CONCLUSIONS}

This study shows that the milk fat globules originating from bovine and goat milk can inhibit the binding and internalization of the foodborne pathogen Salmonella Enteritidis to HT-29 colon cancer cells. This inhibitory effect was apparent only when antibiotic-free medium was used. These results support the hypothesis that the inhibitory effect may not be due only to a simple physical decoy of the surface, although the attachment of fat globules to the cells via mucin cannot be excluded, but that the supramolecular structure of the fat globule membrane may in some way affect the molecules that the bacteria specifically produces to attach to the mucosal membrane and to become internalized. No pronounced differences were observed between different concentrations of milk fat used; however, the highest concentration of milk fat globule $(40 \mathrm{mg} / \mathrm{mL})$ showed the most significant effect in the reduction of adherence and the internalization of bacteria to the cells for both bovine and goat fat globules. Milk fat globules derived from goat milk showed better efficiency than did those derived from bovine milk in vitro, but such a difference may need to be confirmed in vivo because the changes were in the same order of magnitude. Heating of milk before isolation of the fat globules also showed a higher extent of inhibition. The differences observed in samples prepared after heating exclude a specific effect of thermally labile molecules and may suggest that the supramolecular structure of the fat globules and the surface components of the fat globules themselves play a role in this biological functionality.

\section{ACKNOWLEDGMENTS}

This work was partly funded by the Dairy Farmers of Canada (Ottawa, ON, Canada) and the Natural Science and Engineering Council of Canada (Ottawa, ON, Canada). The authors thank Woolwich Dairy Inc. (Orangeville, ON, Canada) for providing the goat milk samples.

\section{REFERENCES}

Allen-Vercoe, E., M. P. Dibb-Fuller, C. J. Thorns, and M. J. Woodward. 1997. SEF17 fimbriae are essential for the convoluted colonial morphology of Salmonella enteritidis. FEMS Microbiol. Lett. 153:33-42.

Atroshi, F., T. Alaviuhkola, R. Schildt, and M. Sandholm. 1983. Fat globule membrane of sow milk as a target for adhesion of K88positive Escherichia coli. Comp. Immunol. Microbiol. Infect. Dis. 6:235-245.

Austin, J. W., G. Sanders, W. W. Kay, and S. Collinson. 1998. Thin aggregative fimbriae enhance Salmonella enteritidis biofilm formation. FEMS Microbiol. Lett. 162:295-301.

Beachey, E. H., B. I. Eisenstein, and I. Ofek. 1981. Sublethal concentrations of antibiotics and bacterial adhesion. Ciba Found. Symp. $80: 288-305$.

Brisson, G., H. F. Payken, P. Sharpe, and R. Jiménez-Flores. 2010. Characterization of Lactobacillus reuteri interaction with milk fat globule membrane components in dairy products. J. Agric. Food Chem. 58:5612-5619.

Corredig, M., and G. D. Dalgleish. 1996. Effect of different heat treatments on the strong binding interactions between whey proteins and milk fat globules in whole milk. J. Dairy Res. 63:441-449.

Desin, T. S., A. L. S. Wisner, P. S. Lam, E. Berberov, C. S. Mickael, A. A. Potter, and W. Köster. 2011. Evaluation of Salmonella enterica serovar Enteritidis pathogenicity island-1 proteins as vaccine candidates against $S$. enteritidis challenge in chickens. Vet. Microbiol. 148:298-307.

Dewettinck, K., R. Rombaut, N. Thienpont, T. T. Le, K. Messens, and J. Van Camp. 2008. Nutritional and technological aspects of milk fat globule membrane material. Int. Dairy J. 18:436-457.

Dobos, K. M., E. A. Spotts, F. D. Quinn, and C. H. King. 2000. Necrosis of lung epithelial cells during infection with Mycobacterium tuberculosis is preceded by cell permeation. Infect. Immun. 68:6300-6310.

EFSA (European Food Safety Authority). 2011. The European Union summary report on trends and sources of zoonoses, zoonotic agents and food-borne outbreaks in 2009. EFSA J. 9:2090.

Gordon, M. A., D. L. Jack, D. H. Dockrell, M. E. Lee, and R. C. Read. 2005. Gamma interferon enhances internalization and early nonoxidative killing of Salmonella enterica serovar Typhimurium by human macrophages and modifies cytokine responses. Infect. Immun. 73:3445-3452.

Jiménez-Flores, R., and G. Brisson. 2008. The milk fat globule membrane as an ingredient: Why, how, when? Dairy Sci. Technol. 88:5-18.

Katsikogianni, M., and Y. F. Missirlis. 2004. Concise review of mechanisms of bacterial adhesion to biomaterials and of techniques used in estimating bacteria-material interactions. Eur. Cell. Mater. $8: 37-57$. 
Kerneis, S., M. F. Bernet, M. H. Coconnier, and A. L. Servin. 1994. Adhesion of human enterotoxigenic Escherichia coli to human mucus secreting HT-29 cell subpopulations in culture. Gut 35:14491454.

Kim, H.-H. Y., and R. Jiménez-Flores. 1995. Heat-induced interactions between the proteins of milk fat globule membrane and skim milk. J. Dairy Sci. 78:24-35.

Kim, Y., K. Sae-Hun, W. Kwang-Youn, K. Young-Jun, and O. Sejong. 2008. Inhibition of Escherichia coli O157:H7 attachment by interactions between lactic acid bacteria and intestinal epithelial cells. J. Microbiol. Biotechnol. 18:1278-1285.

Mellor, G. E., R. M. Goulter, T. W. R. Chia, and G. A. Dykes. 2009. Comparative analysis of attachment of Shiga-toxigenic Escherichia coli and Salmonella strains to cultured HT-29 and Caco-2 cell lines. Appl. Environ. Microbiol. 75:1796-1799.

Newburg, D. S. 2009. Neonatal protection by an innate immune system of human milk consisting of oligosaccharides and glycans. J. Anim. Sci. 87:26-34.

Park, Y. W., M. Juárez, M. Ramos, and G. F. W. Haenlein. 2007. Physico-chemical characteristics of goat and sheep milk. Small Rumin. Res. 68:1-2., 88-113.

Parkash, S., and R. Jenness. 1968. The composition and characteristics of goat's milk: A review. Dairy Sci. Abstr. 30:67-87.

Parker, P., L. Sando, R. Pearson, K. Kongsuwan, R. L. Tellam, and S. Smith. 2010. Bovine Muc1 inhibits binding of enteric bacteria to Caco-2 cells. Glycoconj. J. 27:89-97.

Poppe, C. 1994. Salmonella enteritidis in Canada. Int. J. Food Microbiol. 21:1-5.

Sánchez-Juanes, F., J. M. Alonso, L. Zancada, and P. Hueso., 2009 Glycosphingolipids from bovine milk and milk fat globule membranes: A comparative study. Adhesion to enterotoxigenic Escherichia coli strains. Biol. Chem. 390:31-40.

Sando, L., R. Pearson, C. Gray, P. Parker, P. Hawken, P. C. Thomson, J. R. S. Meadows, K. Kongsuwan, S. Smith, and R. L. Tellam.
2009. Bovine Muc1 is a highly polymorphic gene encoding an extensively glycosylated mucin that binds bacteria. J. Dairy Sci. 92:5276-5291.

Schroten, H., F. G. Hanisch, R. Plogmann, J. Hacker, G. Uhlenbruck, R. Nobis-Bosch, and V. Wahn. 1992. Inhibition of adhesion of Sfimbriated Escherichia coli to buccal epithelial cells by human milk fat globule membrane components: A novel aspect of the protective function of mucins in the nonimmunoglobulin fraction. Infect. Immun. 60:2893-2899.

Schroten, H., C. Stapper, R. Plogmann, H. Köhler, J. Hacker, and F. G. Hanisch. 1998. Fab- independent antiadhesion effects of secretory immunoglobulin A on S-fimbriated Escherichia coli are mediated by sialyloligosaccharides. Infect. Immun. 66:3971-3973.

Shingfield, K. J., Y. Chilliard, V. Toivonen, P. Kairenius, and D. Givens. 2008. Trans fatty acids and bioactive lipids in milk. Adv. Exp. Med. Biol. 606:3-65.

Silanikove, N., G. Leitner, U. Merin, and C. G. Prosser. 2010. Recent advances in exploiting goat's milk: Quality, safety and production aspects. Small Rumin. Res. 89:110-124.

Steele-Mortimer, O. 2008. The Salmonella-containing vacuole-Moving with the times. Curr. Opin. Microbiol. 11:38-45.

Van Immerseel, F., J. De Buck, F. Boyen, L. Bohez, F. Pasmans, J. Volf, M. Sevcik, I. Rychlik, F. Haesebrouck, and R. Ducatelle. 2004. Medium-chain fatty acids decrease colonization and invasion through hilA suppression shortly after infection of chickens with Salmonella enterica serovar Enteritidis. Appl. Environ. Microbiol. 70:3582-3587.

Wang, X., S. Hirmo, R. Willen, and T. Wadstrom. 2001. Inhibition of Helicobacter pylori infection by bovine milk glycoconjugates in a BALB/cA mouse model. J. Med. Microbiol. 50:430-435.

Ye, A., J. Cui, and H. Singh. 2010. Effect of the fat globule membrane on in vitro digestion of the mik fat globules with pancreatic lipase. Int. Dairy J. 20:822-829. 